\section{TRANG CHỦ}

GIỚI THIẸU
TIN TỨC

\section{KINH NGHIEM}

DỊCH Vụ

PHẦN MĖM DI

\title{
Đi tìm bí mật của sự sáng tạo
}

\section{Được viết ngày 21 Tháng tư 2012 Lượt xem: 7356}

Tại sao một số tổ chức lại có tính sáng tạo vượt trội so với tổ chức khác? Điều gì đã giúp cho những tổ chức-doanh nghiệp có năng lực vận hành cao và sáng tạo vượt trội so với những tổ chức khác? Liệu đặc tính sáng tạo và phát kiến có thể được tiếp thu bằng học hỏi và có thể trau dồi?

Đó là những câu hỏi được đặt ra trong cuốn sách mới nhất của Giáo sư Nancy K. Napier viết chung với Mikael Nilsson - một nhà kinh doanh sống và làm việc ở Âu châu - có tựa đề là "The Creative Discipline".

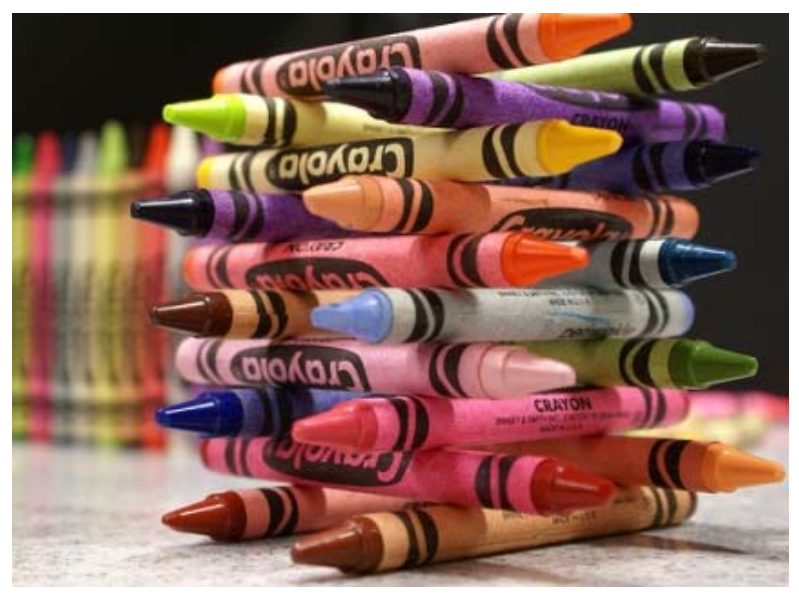

Các chuyên gia - tác giả cuốn sách - nỗ lực trả lời các câu hỏi này và lý giải 6 yếu tố quan trọng nhất giúp thúc đẩy các tổ chức có năng lực mạnh và sức sáng tạo cao. Những nhà kinh doanh cũng học hỏi thêm được cách thức mà những doanh nghiệp năng động sáng tạo có thể thu nhận những kết quảận hành tốt nhất từ những người đồng nghiệp - người lao động - không chỉ thông qua những phương pháp tư duy có kỷ luật nghiêm ngặt, và cả những không gian làm việc thoải mái, những thực hành trong công việc giúp thúc đẩy khả năng tưởng tượng của cá nhân. 
Rất nhiều vấn đề, câu trả lời và ví dụ minh họa hết sức dễ chịu, thuyết phục mà các tác giả đưa ra... Nhưng có lẽ, chỉ có cách tự mình đi qua các vấn đề - lập luận, những điểm thú vị của cuốn sách mới được bộc lộ một cách rõ nét nhất.

Một dẫn chứng người Việt Nam mà GS. Napier đã đưa ra trong cuốn sách là TS. Vương Quân Hoàng đồng sáng lập saga.vn. GS. Napier đã viết: "Thấy những gì người khác không thấy"... Bà cho rằng, "phương pháp tiếp cận của Vương phản ánh thực tại của xã hội Việt Nam: Xông xáo, kiên định hướng tới thịnh vượng, trong một bối cảnh quốc gia đang vượt qua thách thức để hội nhập bức tranh kinh tế khu vực và toàn cầu. Một công việc mới nhất của anh ta là Web site về thông tin và giáo dục kinh doanh, Saga.vn. Anh ta viết sách về kinh doanh, mở văn phòng ở Hà Nội và Sài Gòn, và gia nhập phần nhỏ cư dân Việt Nam có sở hữu xe hơi, số này ở Việt Nam dưới 1\%. Vương đã rà soát môi trường kinh doanh Việt Nam và nhìn ra xa hơn cả thực tại, tự xây dựng kho kiến thức kinh doanh, và nhận thức rõ được những tác động của những thay đổi nhanh chóng Việt Nam đang trải qua, một khi các doanh nghiệp quốc doanh và tư nhân của quốc gia này bước vào trò chơi kinh doanh khu vực và toàn cầu.

Nhưng cũng giống như các nhà kinh doanh Mỹ, anh ta đã làm việc trong rất nhiều năm và trải nghiệm nhiều thất bại. Công ty đầu tiên của anh là công ty dịch vụ đầu tư thành lập năm 2001. Anh ta và một đồng sự mở văn phòng ở một tòa nhà tráng lệ ở Hà Nội, phòng đầy ngộn máy tính và chỉ có hai nhân viên, kích thước phòng chỉ bằng một phần của một buồng ngủ gia đình. Công ty đóng cửa một năm sau đó. Vào thời khắc đó, chẳng mấy người Việt Nam thực sự nắm vững khái niệm đầu tưỉnh, và dĩ nhiên, vì thế thị trường coi như không tồn tại.

Kể từ đó, tuy nhiên, năng lực đọc hiểu môi trường kinh doanh của Hoàng đã tăng lên tới mức gần như hoàn hảo. Anh ta có năng lực nhìn thấy những cơ hội mà người khác mới chỉ bắt đầu học cách nhận biết, và rõ ràng anh ta đã vượt lên trước nhiều đối thủ.

Những nhà kinh doanh sáng tạo như Vương có khả năng cảm nhận đáng kể về ý nghĩa mà môi trường kinh doanh tạo ra cho tổ chức kinh doanh của họ. Họ biết cách phiên dịch những ảnh hưởng, và tìm kiếm nguồn lực để biến những xu hướng đã quan sát thấy trở thành những cơ hội rất tiềm năng. Khi làm việc đó, họ đã có khả năng sáng tạo ra những lợi thế vượt trội so với đối thủ, cho dù là ở Idaho Hoa Kỳ hay là ở Việt Nam. Hiểu biết họ có được có thể đã gồm chứa cả năng lực "đọc hiểu" khách hàng, nhận thức về đối thủ tổng quan hơn, hoặc dự kiến những xu hướng. Họ hành động, bằng cách xây dựng những công ty như Vương đã làm, hoặc sáng tạo ra những nền tảng để phát triển công nghệ và thực nghiệm, như trường hợp của Charlie Fee (một doanh nhân trẻ ở Idaho, Hoa Kỳ - DĐDN).

Giáo sư Nancy K. Napier là học giả nổi tiếng, tác giả của rất nhiều công trình khoa học vang dội và những cuốn sách nghiên cứu rất giá trị. Lĩnh vực nghiên cứu của GS. Napier trải từ các vấn đề quy hoạch nguồn nhân lực, môi trường văn hóa đa quốc gia, sang lĩnh vực đang nóng hổi gần đây về các hệ thống có năng lực sáng tạo-phát minh trong doanh nghiệp. 
Chúng ta không ngạc nhiên khi tên tuổi của N.K. Napier đã khiến cuốn sách mới nhất của bà được xuất bản bởi một trong những nhà xuất bản tên tuổi của thế giới Praeger Publishers. Với 227 trang, cuốn sách chứa đầy nội dung học thuật đan xen với những ví dụ thực, con người thực, địa danh thực đã dẫn người đọc tới những suy nghĩ tiếp về năng lực sáng tạo, khả năng tổức-điều phối và ý nghĩa cuối cùng của sự sáng tạo trong doanh nghiệp. Hiển nhiên, các nội dung này liên quan chặt chẽ tới hoạt động đang ngày càng được chú ý, và nhiều nơi là sự sống còn, hoạt đông Nghiên cứu \& Phát triển, vẫn được biết tới với cái tên viết tắt $R \& D$.

Theo dddn.vn

\begin{tabular}{lll}
\hline Thich 0 Thia sẻ & Tweet
\end{tabular}

Save

Chia sẻ

\section{Bài viết liên quan:}

14/05/2020 - Chăm sóc khách hàng là gì?

11/05/2020 - Phần mềm KPI - Công cụ hướng tới mục tiêu kinh doanh hiệu quả

04/05/2020 - Trả lương 3P trong doanh nghiệp nhà nước như thế nào?

29/04/2020 -

Dạy và học online - kết nối tri thức đến hàng triệu học sinh/sinh viên giữa thời khủng khoảng đại dịch toàn cầu

24/04/2020 - Doanh nghiệp bạn đang sử dụng phần mềm KPI hay KRI?

22/04/2020 - Cấu phần lương cơ bản trong doanh nghiệp và một số tiêu thức khi trả lương

20/04/2020 - Có nên tích hợp CRM với hệ thống quản lý giao dịch lõi?

20/04/2020 - Xu hướng mua sắm trong tương lai - Chỉ cần một cú chạm hay click chuột

19/04/2020 - Amazon đã ứng dụng Big Data để hiểu khách hàng như thế nào?

17/04/2020 - Vượt rào vòng loại CV nhờ tư duy đúng về kỹ năng

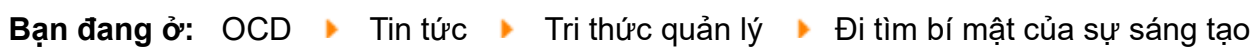

\section{KÉT NÓI VỚI OCD ～LIÊN HẸ VỚI OCD}

02435537799

0963636066

ocd@ocd.vn

ĐÃ THÔNG BÁO

Bộ CÔNG THƯơNG
Công ty Tư vấn Quản lý OCD

Trụ sở HN: Tầng 18, Tòa nhà Vi Tel: 02435537799 Fax: 024

Văn phòng HCM: B0609, Tòa $B$ HCMC

Tel: 02839253985 | 090665501 |

CÔNG TY TƯ VÂN QUẢN LÝ O

TP. Hà Nội cấp ngày 23/05/200:

Chính sách bảo mật thông 1

Điều khoản sử dụng 